\title{
PROPRIEDADES TÉRMICAS E FÍSICO-QUÍMICAS DE BLENDAS DE BANHA SUÍNA E ÓLEO DE FARELO DE ARROZ OBTIDAS POR INTERESTERIFICAÇÃO QUÍMICA
}

\author{
P. P. da SILVA ${ }^{1}$, F. R. SOBRAL ${ }^{1}$, J. RIZZI ${ }^{1}$, R. S. POHNDORF ${ }^{1}$ e L. A. de A. PINTO ${ }^{1}$ \\ ${ }^{1}$ Universidade Federal do Rio Grande, Escola de Química e Alimentos \\ E-mail para contato: dqmpinto@furg.br
}

\begin{abstract}
RESUMO - O objetivo deste estudo foi obter um lipídio estruturado através da reação de interesterificação química de blendas de banha suína com óleo de farelo de arroz. As blendas elaboradas seguiram as seguintes proporções (banha suína:óleo de farelo de arroz) 100:0, 0:100, 90:10, 70:30 e 50:50 (m/m). O índice de iodo variou proporcionalmente entre as blendas de $69,6 \pm 1,2 \mathrm{cgI}_{2} \mathrm{~g}^{-1}$ na banha suína para 99,2 $\pm 1,4 \mathrm{cgI}_{2} \mathrm{~g}^{-1}$ no óleo de farelo de arroz, não apresentando diferença significativa $(p>0,05)$ nos seus valores antes ou após a reação de interesterificação. Ocorreu uma diminuição no índice de acidez e um aumento no índice de peróxidos após a reação. $\mathrm{O}$ ponto de fusão da banha suína foi $32,8{ }^{\circ} \mathrm{C}$ e diminuiu para $23,8{ }^{\circ} \mathrm{C}$ após a interesterificação com $50 \%$ de óleo de arroz. O teor de gordura sólida da banha suína à $25^{\circ} \mathrm{C}$ foi de $34 \%$, porém, sua blenda com $50 \%$ de óleo de farelo de arroz diminuiu o teor de gordura sólida para $8 \%$. Este estudo demonstrou que a interesterificação química é efetiva para modificar as propriedades físico-químicas da banha suína, óleo de farelo de arroz e suas misturas.
\end{abstract}

\section{INTRODUÇÃO}

O lipídio estruturado é um composto que apresenta características físicas, químicas e nutricionais diferentes dos lipídios que lhes deram origem, podendo apresentar a capacidade de reduzir o risco de doenças e ser chamado de alimento funcional (Norizzah et al., 2004). A elaboração de um lipídio estruturado pode ser realizada mediante a mistura e interesterificação com o rearranjo de ácidos graxos na molécula de glicerol. A reação de interesterificação pode ocorrer de forma química ou enzimática, e é capaz de promover modificações nas propriedades dos óleos. A indústria de óleos tem despertado interesse na interesterificação principalmente para produção de margarinas com menor teor de gordura trans, provocadas pelo processo de hidrogenação.

Nas gorduras de origem animal como sebo bovino e banha suína predominam ácidos graxos saturados (palmítico e esteárico), que são caracterizados por provocarem doenças cardiovasculares (Rousseau e Marangoni, 1999). Em contraste, óleos vegetais contêm em torno de $70-80 \%$ de ácidos graxos insaturados, que podem causar mudanças favoráveis nos níveis de colesterol, sendo benéficos à saúde (Klinkersorn et al., 2004). O óleo de farelo de arroz é um óleo vegetal obtido como um subproduto do processamento de grãos de arroz e apresenta em sua composição alto teor de ácidos graxos insaturados $(>75 \%)$ e antioxidantes 
naturais como o y-orizanol (Lerma-García et al., 2009). Assim, a produção de lipídios estruturados obtidos de gordura animal e óleos vegetais torna-se promissora.

O objetivo deste estudo foi desenvolver e avaliar os lipídios estruturados obtidos através da reação de interesterificação química da gordura suína e suas blendas com óleo de arroz. Para isto, foram comparadas as variações no grau de insaturação e oxidação dos lipídios, assim como o efeito da temperatura no ponto de fusão e no teor de gordura sólida das blendas interesterificadas.

\section{MATERIAIS E MÉTODOS}

\subsection{Materiais}

O óleo de farelo de arroz (OFA) branqueado foi adquirido em indústria na cidade de Pelotas, e mantido à $-20{ }^{\circ} \mathrm{C}$ para reduzir o processo oxidativo. Banha suína foi obtida no comércio local. Os experimentos foram realizados no Laboratório de Operações Unitárias da Universidade Federal do Rio Grande (FURG).

\subsection{Reação de interesterificação}

A reação de interesterificação foi conduzida utilizando banha suína e óleo de arroz branqueado. As blendas $(100 \mathrm{~g})$ foram aquecidas a $70^{\circ} \mathrm{C}$ em chapa de aquecimento com agitação constante $(500 \mathrm{rpm})$ por $30 \mathrm{~min}$ e sob pressão absoluta de $60 \mathrm{mmHg}$, de acordo com procedimento adaptado de Silva et al. (2009). As blendas foram elaboradas nas seguintes proporções (banha suína:óleo de arroz): 100:0, 0:100, 90:10, 70:30 e 50:50 (m/m). As misturas (blendas não interesterificadas) foram separadas para posterior análise e a reação de interesterificação foi iniciada pela adição de $0,5 \%(\mathrm{~m} / \mathrm{v})$ de catalisador metóxido de sódio em pó, nas mesmas condições da elaboração das blendas. Após $30 \mathrm{~min}$ foi adicionada água destilada, para finalizar a reação e evitar o escurecimento, e sulfato de sódio anidro para reter umidade. Posteriormente, o produto interesterificado foi filtrado a quente.

\subsection{Análises de caracterização}

Os termogramas de fusão foram obtidos através de Calorimetria Exploratória Diferencial (DSC) (Shimadzu, DSC-60, Japão). Amostras (5 mg) foram hermeticamente seladas em cadinhos de alumínio e resfriadas em uma taxa de $10^{\circ} \mathrm{C} / \mathrm{min}$ até $50^{\circ} \mathrm{C}$, e então aquecidas até $50^{\circ} \mathrm{C}$ (Fauzi et al., 2013). O teor de gordura sólida foi obtido através da integração dos termogramas de fusão (Khatoon e Reddy, 2005). Os produtos de oxidação primária foram determinados através do índice de peróxidos de acordo com o método Cd 8-53 da AOCS (1998). O índice de acidez foi determinado pelo método Ca 5a-40 da AOCS (1998), e expresso $\mathrm{g}_{\mathrm{KOH}} / 100 \mathrm{~g}_{\text {óleo }}$. $\mathrm{O}$ índice de iodo foi determinado pelo Método de Wijs conforme o método Cd 1-25 da AOCS (1998).

\subsection{Análise estatística}

Os tratamentos foram realizados em réplica $(n=2)$ e as análises em triplicata $(n=3)$. A análise estatística dos tratamentos foi feita pelo método de Tukey a 95\% de significância $(\mathrm{p}<0,05)$ utilizando o software Statistica 7.0 (Statsoft, EUA). 


\section{RESULTADOS E DISCUSSÃO}

As avaliações das blendas de banha suína e óleo de arroz, antes e após a reação de interesterificação, foram analisadas pelo índice de iodo, índice de acidez e índice de peróxidos (Tabela 1). O índice de iodo está relacionado com o grau de insaturação dos ácidos graxos e variou proporcionalmente em relação às blendas, não apresentando diferença significativa ( $>00,05)$ após a reação de interesterificação. Os valores obtidos para o índice de iodo estão de acordo com a literatura. Segundo O'Brien (1998), o índice de iodo da banha varia entre 46 e $70 \mathrm{cgI}_{2} \mathrm{~g}^{-1}$. O óleo de farelo de arroz apresenta índice de iodo compreendido entre 96 e 101 $\operatorname{cgI}_{2} \mathrm{~g}^{-1}$ (Silva e Gioielli, 2006). O índice de acidez diminui após a reação de interesterificação indicando que os ácidos graxos livres foram ligados às moléculas de glicerol. Com relação à oxidação, o índice de peróxidos apresentou diferença significativa $(\mathrm{p}<0,05)$ antes e após a interesterificação para as blendas que contêm 30 e $50 \%$ de óleo de farelo de arroz. O tempo e a temperatura da reação são fatores que podem ter contribuído para a oxidação do óleo.

Tabela 1 - Caracterização da banha suína, óleo de farelo de arroz e suas blendas, antes e após a interesterificação química

\begin{tabular}{llll}
\hline $\begin{array}{l}\text { Relação banha suína:óleo de arroz } \\
(\mathrm{m} / \mathrm{m})\end{array}$ & $\begin{array}{l}\text { Índice de } \\
\text { iodo } \mathrm{cgI}_{2} \mathrm{~g}^{-1}\end{array}$ & $\begin{array}{l}\text { Índice de } \\
\text { acidez }(\mathrm{g} / 100 \mathrm{~g})\end{array}$ & $\begin{array}{l}\text { Índice de } \\
\text { peróxidos } \\
(\mathrm{meq} / \mathrm{kg})\end{array}$ \\
\hline $100: 0$ & $69,6 \pm 1,2^{\mathrm{d}}$ & $0,34 \pm 0,05^{\mathrm{a}}$ & $3,18 \pm 0,41^{\mathrm{ab}}$ \\
$0: 100$ & $99,2 \pm 1,4^{\mathrm{a}}$ & $0,32 \pm 0,06^{\mathrm{a}}$ & $3,97 \pm 0,43^{\mathrm{ab}}$ \\
Antes da interesterificação & & & \\
$90: 10$ & $71,1 \pm 1,2^{\mathrm{d}}$ & $0,32 \pm 0,06^{\mathrm{a}}$ & $3,03 \pm 0,39^{\mathrm{ab}}$ \\
$70: 30$ & $78,5 \pm 1,3^{\mathrm{c}}$ & $0,38 \pm 0,05^{\mathrm{a}}$ & $2,69 \pm 0,42^{\mathrm{b}}$ \\
$50: 50$ & $82,6 \pm 1,0^{\mathrm{b}}$ & $0,42 \pm 0,05^{\mathrm{a}}$ & $2,62 \pm 0,47^{\mathrm{b}}$ \\
Após a interesterificação & & & \\
$90: 10$ & $70,2 \pm 0,9^{\mathrm{d}}$ & $0,14 \pm 0,04^{\mathrm{b}}$ & $3,32 \pm 0,36^{\mathrm{b}}$ \\
$70: 30$ & $77,8 \pm 1,0^{\mathrm{c}}$ & $0,20 \pm 0,05^{\mathrm{b}}$ & $4,53 \pm 0,30^{\mathrm{a}}$ \\
$50: 50$ & $83,8 \pm 1,1^{\mathrm{b}}$ & $0,15 \pm 0,04^{\mathrm{b}}$ & $4,51 \pm 0,43^{\mathrm{a}}$ \\
\hline
\end{tabular}

*Médias \pm desvio padrão. Letras iguais na mesma coluna não diferem estatisticamente $(p>0,05)$.

O somatório dos ácidos graxos saturados de banha suína constitui cerca de $40 \%$ do total de ácidos graxos, com destaque para os ácidos palmítico (25\%) e esteárico (13\%) (Silva et al., 2009). No óleo de farelo de arroz, o total de ácidos graxos insaturados é superior a $75 \%$ e apresenta elevado teor de ácido linoléico (35\%), o que resulta na diminuição do ponto de fusão do óleo devido suas duplas ligações, quando comparado com a banha (Figura 1). A curva de fusão do óleo de farelo de arroz apresentou dois picos, o primeiro na temperatura de $-15,9{ }^{\circ} \mathrm{C}$ que pode ser atribuído ao ponto de fusão do ácido linoléico presente nos triglicerídeos e o segundo na temperatura de $-7,5^{\circ} \mathrm{C}$, devido ao ácido oléico (Figura 1A). A banha suína também apresentou dois picos nas temperaturas de $-0,2{ }^{\circ} \mathrm{C}$ e $32,8{ }^{\circ} \mathrm{C}$, estando estes relacionados ao elevado teor de ácido oléico e palmítico, respectivamente (Figura 1B). A adição de óleo de farelo de arroz nas blendas com banha suína resultou na progressiva 
diminuição dos picos de fusão dos lipídios estruturados. A blenda composta por $90 \%$ de banha e $10 \%$ de óleo de farelo de arroz apresentou um pico de fusão na temperatura de 28,8 ${ }^{\circ} \mathrm{C}$ e um valor de entalpia de $14,6 \mathrm{~J} / \mathrm{g}$. Entretanto, a blenda com $50 \%$ de banha e $50 \%$ de óleo de farelo de arroz resultou na diminuição do ponto de fusão para $23,8{ }^{\circ} \mathrm{C}$ e da entalpia para $7,1 \mathrm{~J} / \mathrm{g}$. Consequentemente, menos energia é necessário para fundir a blenda quanto maior for a adição de óleo farelo de arroz. Resultados semelhantes foram obtidos por Silva et al. (2009), que observaram uma diminuição no ponto de amolecimento da banha suína a medida que óleo de soja era adicionado.

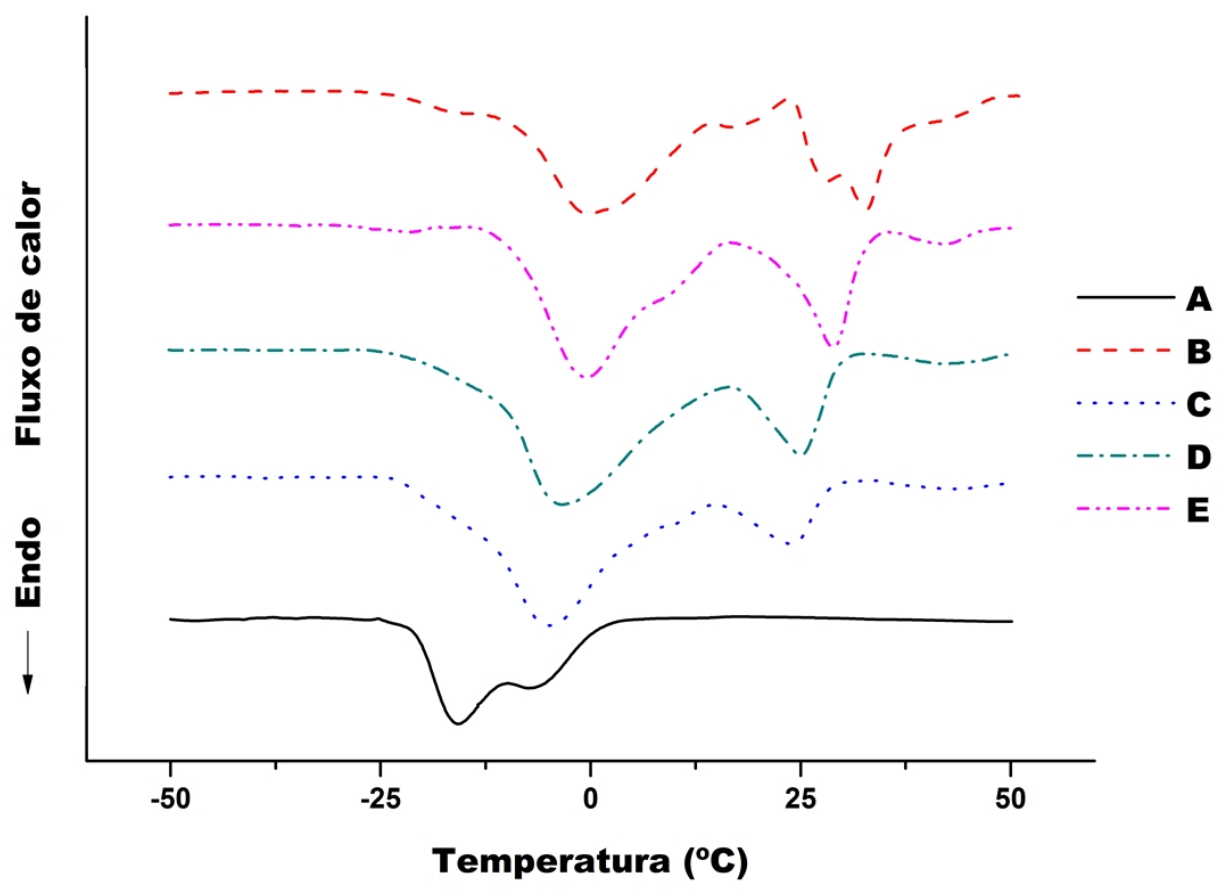

Figura 1 - Termogramas de fusão de (A) óleo de farelo de arroz, (B) banha suína, (C) blenda interesterificada de banha:óleo de arroz (50:50), (D) blenda interesterificada de banha:óleo de arroz (70:30) e (E) blenda interesterificada de banha:óleo de arroz (90:10)

O teor de gordura sólida relaciona percentualmente a quantidade de cristais presente na gordura em função de sua temperatura. O teor de gordura sólida confere diferentes características ao produto como facilidade de embalagem, fluidez, consistência, exsudação e propriedades organolépticas (Soares et al., 2009). O óleo de farelo de arroz praticamente não apresentou gorduras sólidas em temperaturas acima de $0{ }^{\circ} \mathrm{C}$ (Figura 2A). Porém, a banha suína somente apresentou baixo teor de gordura sólida $(<5 \%)$ em temperaturas superiores a 40 ${ }^{\circ} \mathrm{C}$. No geral, maiores quantidades de óleo de arroz nas blendas com banha promoveram uma diminuição no teor de gordura sólida. Por exemplo, na temperatura de $25^{\circ} \mathrm{C}$ a banha suína apresentou um teor de gordura sólida de $34 \%$ e na blenda interesterificada com de óleo de farelo de arroz (50:50) este valor diminuiu para $8 \%$. 

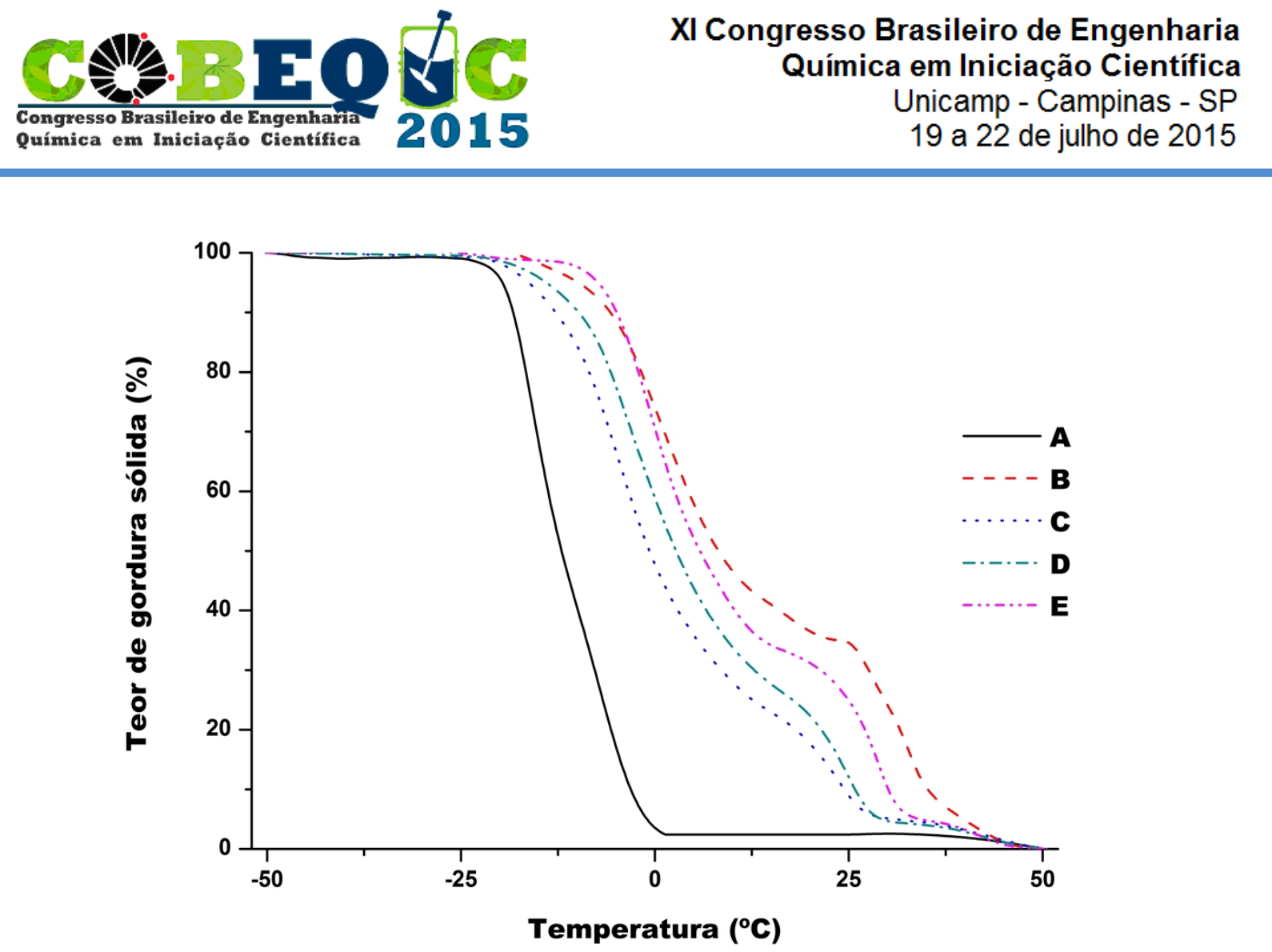

Figura 2 - Teor de gordura sólida de (A) óleo de farelo de arroz, (B) banha suína, (C) blenda interesterificada de banha:óleo de arroz (50:50), (D) blenda interesterificada de banha:óleo de arroz (70:30) e (E) blenda interesterificada de banha:óleo de arroz (90:10)

\section{CONCLUSÃO}

A interesterificação química de banha suína com óleo de farelo de arroz produziu um novo triacilglicerol com características físico-químicas diferentes dos produtos originais. Após a reação de interesterificação houve uma diminuição do índice de acidez e aumento no índice de peróxidos. A formação de blendas promoveu uma diminuição no ponto de fusão e do teor de gordura sólida após a interesterificação.

\section{REFERÊNCIAS}

AOCS. Official and tentative methods of the American Oil Chemist's Society. Chicago, USA: American Oil Chemists' Society Press, 1998.

FAUZI, S. H. M.; RASHID, N. A.; OMAR, Z. Effects of chemical interesterification on the physicochemical, microstructural and thermal properties of palm stearin, palm kernel oil and soybean oil blends. Food Chem., v. 137, p. 8-17, 2013.

KHATOON, S.; REDDY, S. R. Y. Plastic fats with zero trans fatty acids by interesterification of mango, mahua and palm oils. Eur. J. Lipid Sci. Technol, v. 107, p. 786-791, 2005. 
KLINKERSORN, U.; H-KITTIKUN. A.; CHINACHOTI, P.; SOPHANODORA, P. Chemical transesterification of tuna oil to enriched omega-3 polyunsaturadet fatty acids. Food Chem., v. 87, p. 415-421, 2004.

LERMA-GARCÍA, M. J.; HERRERO-MARTÍNEZ, J. M.; SIMÓ-ALFONSO, E. F.; MENDONÇA, C. R. B.; RAMIS-RAMOS, G. Composition, industrial processing and applications of rice bran $\gamma$-oryzanol. Food Chem., v. 115, p. 389-404, 2009.

NORIZZAH, A. R.; CHONG, C. L.; CHEOW, C. S.; ZALIHA, O. Effects of chemical interesterification on physicochemical properties of palm stearin and palm kernel olein blends. Food Chem, v. 86, p. 229-235, 2004.

O'BRIEN, R. D. Fats and oils - Formulating and processing for applications. Lancaster: Pa. Technomic Pub. Co., 1998.

ROUSSEAU, D.; MARANGONI, A. The effects of interesterification on physical and sensory attributes of butterfat and butterfat-canola oil spreads. Food Res. Int., v. 31, p. 381-388, 1999.

SILVA, R. C.; COTTING, L. N.; POLTRONIERI, T. P.; BALCÃO, V. M.; ALMEIDA, D. B.; GONCALVES, L. A. G.; GRIMALDI, R.; GIOIELLI, L A. The effects of enzymatic interesterification on the physical-chemical properties of blends of lard and soybean oil. LWT Food Sci. Technol., v. 42, p. 1275-1282, 2009.

SILVA, R. C.; GIOIELLI, L. A. Propriedades físicas de lipídios estruturados obtidos a partir de banha e óleo de soja. Rev. Bras. Cienc. Farm., v. 42, p. 223-235, 2006.

SOARES, F. A. S. M.; SILVA, R. C.; SILVA, K. C. G.; LOURENÇO, M. B.; SOARES, D. F.; GIOIELLI, L. A. Effects of chemical interesterification on physicochemical properties of blends of palm stearin and palm olein. Food Res. Int., v. 42, p. 1287-1294, 2009. 